\title{
Role of endoscopy in the investigation of upper gastrointestinal symptoms in HIV-infected patients
}

\author{
C Mel Wilcox MD
}

\begin{abstract}
CM Wilcox. Role of endoscopy in the investigation of upper gastrointestinal symptoms in HIV-infected patients. Can J Gastroenterol 1999;13(4):305-310. Endoscopy plays a pivotal role in the management of patients with the acquired immunodeficiency syndrome (AIDS), because tissue documentation of opportunistic processes is often necessary to establish a definitive diagnosis. With progression of immunodeficiency, endoscopy becomes more important because the predisposition to opportunistic disorders of the gastrointestinal tract is greatly increased. The yield of upper endoscopy in human immunodeficiency virus (HIV)-infected patients is dependent upon the indication for the procedure, including the clinical presentation and the stage of immunodeficiency. Indications for which endoscopy has a high yield include AIDS with esophageal symptoms refractory to empirical antifungal therapy, small bowel biopsy for chronic severe diarrhea and upper gastrointestinal bleeding. Although processes can be identified, a diagnosis is less likely in patients who present with nausea and vomiting or nonspecific abdominal pain. By tailoring the use of endoscopy to the presenting symptoms and CD4 lymphocyte count, the diagnostic benefit can be increased.
\end{abstract}

Key Words: Acquired immunodeficiency syndrome; Endoscopy; Human immunodeficiency virus

\section{Le rôle de l'endoscopie en présence de symptômes des voies digestives supérieures chez des patients infectés par le VIH}

\begin{abstract}
RÉSUMÉ : L'endoscopie joue un rôle central dans la prise en charge des patients souffrant du syndrome de l'immunodéficience acquise (SIDA) parce que la documentation signes tissulaires des processus opportunistes s'impose souvent pour la confirmation du diagnostic. $\grave{A}$ mesure que l'immunodéficience progresse, l'endoscopie devient plus importante en raison de la prédisposition croissante des patients aux troubles opportunistes affectant les voies digestives. Le rendement de l'endoscopie des voies digestives supérieures en présence du virus de l'immunodéfi. cience humaine (VIH) dépend de l'indication de l'intervention, y compris le tableau clinique et le stade de l'immunodéficience. Les indications pour lesquelles l'endoscopie donne un bon rendement sont le SIDA accompagné de symptômes œesophagiens réfractaires aux antifongiques empiriques, la biopsie du grêle dans les cas de diarrhée grave et l'hémorragie des voies digestives hautes. Bien que ces processus pathologiques soient identifiables, le diagnostic est plus probable chez des patients qui souffrent de nausées et de vomissements ou de douleurs abdominales non spécifiques. En ajustant l'utilisation de l'endoscopie en fonction des symptômes et de la numération des CD4, l'avantage diagnostique peut être amélioré.
\end{abstract}

$\mathrm{T}$ he gastrointestinal tract is a common target for a variety of processes in patients with the acquired immunodeficiency syndrome (AIDS). Endoscopy plays a critical role in the management of these patients because opportunistic infections and neoplasms that involve the gut are best diagnosed histologically. Because upper endoscopy is commonly used in AIDS patients, there has been interest in better de- fining its indications as well as the endoscopic approach to identified lesions.

Several different philosophies guide the endoscopic approach to human immunodeficiency virus (HIV)-infected patients with upper gastrointestinal symptoms. Some physicians routinely perform endoscopy early on in the symptomatic patient given the possibility of an opportunistic

Department of Medicine, Division of Gastroenterology and Hepatology, The University of Alabama at Birmingham, Birmingham, Alabama

Correspondence: Dr C Mel Wilcox, Division of Gastroenterology and Hepatology, University of Alabama at Birmingham, Birmingham, Alabama 35294-0007, USA. Telephone 205-975-4958, fax 205-934-1537, e-mail mel_wilcox@gihep.uab.edu

Received for publication July 9, 1998. Accepted October 22, 1998 


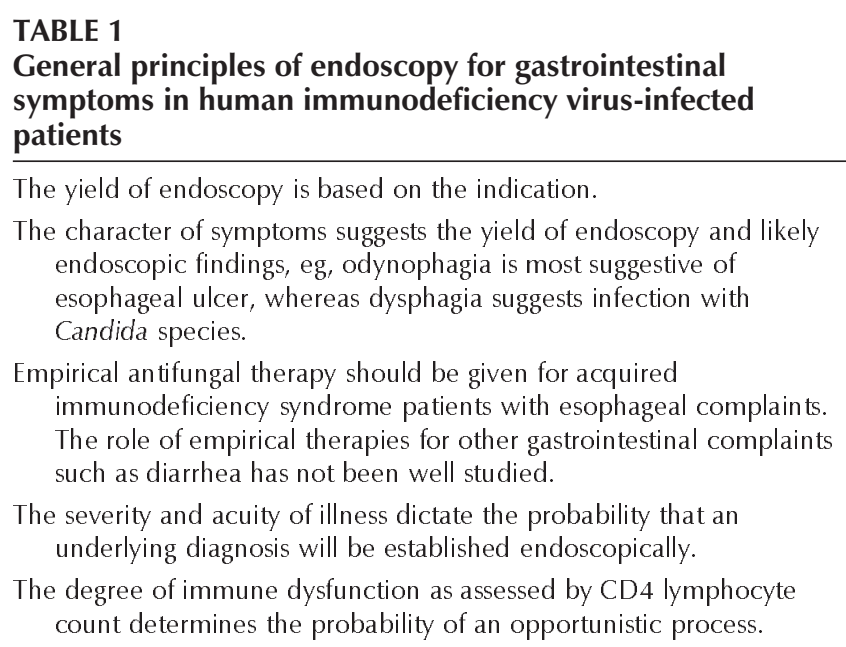

process. In contrast, others institute multiple empirical trials before considering endoscopic evaluation. A pragmatic strategy used by many physicians employs empirical therapy directed towards the most common cause of the symptoms followed by endoscopy for patients who fail to respond clinically. Endoscopy can thus be considered part of a stepwise approach to evaluation such that noninvasive tests or empirical therapy are initially used followed by endoscopy.

To address the role of endoscopy in the evaluation of upper gastrointestinal symptoms in HIV-infected patients, the relative yield of endoscopy based on the clinical presentation rather than organ system or causes of disease is examined. Indeed, it is the presenting complaint that determines the approach to management, including the decision to perform endoscopy. Although a clear understanding of the rationale for and yield of endoscopy in these patients is important, the widespread use of highly active antiretroviral therapy (HAART), which includes protease inhibitors, has dramatically reduced the incidence of opportunistic infections, including those involving the gastrointestinal tract (1). This change in the natural history of HIV disease will necessarily prompt a reassessment of the etiology and management of gastrointestinal disorders in these patients.

\section{RATIONALE FOR ENDOSCOPY}

In general, the indications for upper endoscopy in HIVinfected patients are similar to those in any other patient, and endoscopy should be viewed as both a diagnostic and therapeutic tool. Because some infections can be accurately diagnosed serologically (blood) or microbiologically (blood, stool), endoscopic evaluation is not always required. However, tissue involvement by neoplasms and certain infections, such as cytomegalovirus (CMV), can only be conclusively established by mucosal biopsy, thereby mandating endoscopy. In addition, the frequency of coinfections in AIDS underscores the importance of endoscopic examination with biopsy. For patients with severe upper gastrointestinal symptoms, endoscopy can also expedite the diagnostic process such that appropriate therapy can be instituted. It is hoped that by establishing the diagnosis, morbidity is re- duced, quality of life improved and survival extended. Although these goals for endoscopy, as with those for any other diagnostic modality, are the ultimate objectives, little attention has focused on the impact of endoscopy on these outcome measures. Nevertheless, a general consensus exists that, for many gastrointestinal disorders that complicate AIDS, endoscopy with biopsy establishes a definitive diagnosis and, given the efficacy of available therapies, reduces morbidity. Long term survival, however, is determined by the degree of underlying immune dysfunction and ability to control HIV replication medically (2-4).

\section{GENERAL PRINCIPLES}

A number of principles, many of which are unique to these patients, should guide the approach to endoscopy in HIV infected patients (Table 1). The likelihood that endoscopy will identify a specifically treatable opportunistic or nonopportunistic disorder is determined by the clinical presentation, indication for endoscopy and degree of immunodeficiency (5). For example, endoscopy in a patient with hematemesis usually identifies a lesion, whereas in a patient with preserved immune function and vague dyspepsia, endoscopy is of low yield. The character of the symptoms often suggests the likelihood of a specific disorder. Finally, assessment of immune function cannot be overemphasized as an integral tool for formulating a differential diagnosis. It is well established that the prevalence and incidence of opportunistic infections and neoplasms of the gastrointestinal tract in HIV-infected patients are based on the severity of immune function (2,5-7). In general, opportunistic processes do not manifest until immune function is severely compromised (CD4 lymphocyte count less than $200 / \mathrm{mm}^{3}$ ). Some infections, such as CMV and Mycobacterium avium complex (MAC), are rarely observed until the CD4 lymphocyte count falls to less than $100 / \mathrm{mm}^{3}(8)$; the median CD4 count in patients with MAC is less than $50 / \mathrm{mm}^{3}(6,7)$. Therefore, in the symptomatic patient, the degree of immune dysfunction - reflected by the CD4 lymphocyte count - dictates the likelihood of an opportunistic process.

\section{ESOPHAGEAL COMPLAINTS}

Before the availability of HAART, esophageal disease complicated HIV infection in up to one-third of patients, usually in the later stages of immunodeficiency (9). Studies have consistently identified candidiasis as the most common cause of esophageal symptoms, occurring in $30 \%$ to $60 \%$ of patients $(10-12)$. Often, candidiasis is a coinfection with some other process $(11,13)$. After candidiasis, viral infections are next in importance, with CMV being much more common than herpes simplex virus (HSV) infection. Idiopathic esophageal ulcer (IEU), a diagnosis of exclusion, is also common in these patients. In a prospective trial of 100 HIV-infected patients with esophageal ulcers, CMV was found either alone or in combination with some other processes in 51\%, while IEU was diagnosed in $41 \%$ (14).

The character of the esophageal complaint(s) plays a role in suggesting the underlying cause. In a study evaluating the 
yield of upper endoscopy in HIV-infected patients, Bashir and Wilcox (5) found that of the 85 patients in whom odynophagia was the primary symptom, an esophageal ulcer was identified in $76 \%$. In contrast, of the 17 patients in whom dysphagia was the primary symptom, esophageal ulcer was found in only $12 \%$, whereas esophageal candidiasis was identified in $24 \%$, and no esophageal or gastric abnormalities were observed in $46 \%$. Other studies have also found that esophageal ulcer characteristically causes odynophagia $(12,14)$. Thus, although it is difficult to predict with certainty the underlying esophageal disease based on symptoms alone, in the patient with severe odynophagia in whom dysphagia is absent, an underlying esophageal ulcer is highly likely, which warrants earlier consideration of endoscopy (15).

Because Candida species are the most common cause of esophageal disease in patients with AIDS, studies have addressed the utility of empirical fluconazole as an initial diagnostic strategy. We (12) randomly assigned 134 HIVinfected patients with new-onset esophageal symptoms to either endoscopy or empirical fluconazole. Fluconazole was given as a $200 \mathrm{mg}$ oral loading dose followed by $100 \mathrm{mg}$ orally daily. For the 68 patients randomly assigned to endoscopy, candida esophagitis alone was diagnosed in $65 \%$, candidiasis in combination with ulcer in $14 \%$ and ulcer alone in $15 \%$. Of the 66 patients randomly assigned to empirical fluconazole, $56(85 \%)$ experienced complete symptomatic resolution. Importantly, 47 of these patients (84\%) had a complete symptomatic response to fluconazole by one week. Although a complete response was not observed until three weeks in two patients, it should be noted that all patients experienced some symptomatic improvement within the first week. We and others have shown a rapid clinical response to fluconazole in trials evaluating the efficacy of fluconazole for candida esophagitis $(16,17)$. Of the 12 patients $(18 \%)$ who did not clinically improve with fluconazole, endoscopy revealed an esophageal ulcer in 10 and hypopharyngeal disease in one, and was normal in one patient (12). This empirical approach was found to be highly cost effective, and no patient failing empirical fluconazole had a complication (eg, bleeding) before definitive endoscopic examination. A cost effective study using Markov modelling reached similar conclusions (18).

These studies $(12,18)$ suggest that, in general, HIV infected patient with esophageal symptoms who are at risk of opportunistic infections (CD4 lymphocyte count less than $200 / \mathrm{mm}^{3}$ ) should first undergo empirical antifungal therapy; endoscopy should be reserved for those who fail to improve. The presence of thrush increases the likelihood of concomitant esophageal candidiasis and, therefore, favours a strategy of initial empirical therapy (19). Given the efficacy of fluconazole for candidiasis infections, we use it as first-line therapy $(20,21)$. Although not studied for empirical therapy, the efficacy of itraconazole for candida esophagitis suggests that this agent is also effective (22). Ketoconazole should not be used because of its documented inferiority to fluconazole and the potential for drug interaction in these patients $(21,23)$.
For the patient with severe symptoms requiring hospitalization, unless candida esophagitis is very likely, endoscopy is warranted to expedite the diagnosis, institute specific therapy and reduce the duration of the hospital stay.

The rapid symptomatic improvement of candida esophagitis with fluconazole has important implications for the appropriate use of empirical therapy. If the patient does not clinically improve within one week of initiating fluconazole, endoscopy should be considered rather than observation for an additional week of therapy. We (24) have shown a high prevalence of esophageal ulcer in nonresponders. Likewise, given the broad range of potential underlying etiologies of esophageal disease in AIDS, it is unlikely that providing other empirical therapies would generally be beneficial; they are expensive and have potential toxicity. A specific diagnosis of the esophageal disease is appropriate given the efficacy of therapies for the broad range of etiologies including CMV and HSV (23). Complete healing of IEU can be achieved with oral prednisone (25) and thalidomide (26), although the relapse rate is high (14).

Patients with symptoms typical of gastroesophageal reflux disease should receive appropriate anti-acid therapy rather than empirical fluconazole, particularly when the CD4 lymphocyte count is greater than $200 / \mathrm{mm}^{3}$ and thrush is absent. Although a barium esophagram may identify abnormalities in the symptomatic patient, the radiographic findings are rarely specific enough to warrant institution of therapy and may be falsely negative $(27,28)$. Furthermore, if an esophageal ulcer or mass lesion is identified on barium study, endoscopy with biopsy is still required for a definitive diagnosis. To increase sensitivity, we believe that multiple biopsies (approximately 10) should be taken from the base of esophageal ulcers to differentiate CMV ulcer from IEU (29). For shallow ulcers, biopsy from the ulcer edge (to obtain squamous tissue) is important to exclude HSV esophagitis.

\section{DYSPEPSIA}

Dyspepsia, defined as abdominal pain located in the upper abdomen, has received little attention in HIV-infected patients. Most studies have categorized HIV-infected patients with upper abdominal symptoms and signs into either esophageal complaints, nausea and vomiting, or a complication such as bleeding. Diagnostic considerations for the HIV infected patient with dyspepsia include gastroesophageal reflux disease, gastroesophageal junction ulceration (infectious or idiopathic), and gastric or duodenal mucosal disease. Although a variety of infections have been reported to involve the stomach, usually during the process of widespread lymphohematogenous dissemination, clinically apparent gastric infections are infrequent. The most common opportunistic infection of the stomach is CMV. Gastric neoplasms including non-Hodgkin's lymphoma and Kaposi's sarcoma (KS) may complicate HIV infection. Indeed, the stomach is one of the most common gastrointestinal sites for involvement by KS. Whereas gastric KS is usually asymptomatic, gastric lymphoma characteristically presents with epigastric pain often associated with vomiting or bleeding. 
Despite the young age of most patients with HIV infection, peptic ulcer disease is uncommon. The reason(s) for this relative infrequency is unknown. One possibility is a low prevalence of Helicobacter pylori infection. However, most (30-32) but not all (33) studies suggest that $H$ pylori infection, as assessed either serologically or histologically, is as common in HIV-infected patients as in appropriately matched controls. Another speculation for the infrequency of ulcer disease in these patient is the widespread use of antibiotics, which may eradicate pre-existing $H$ pylori infection $(32,33)$; however, multiple antibiotics combined with antiacid therapy are generally required to eradicate $H$ pylori infection successfully. Hypochlorhydria, whose pathogenesis remains undefined, has been documented in up to $25 \%$ of patients with AIDS $(34,35)$; this phenomenon may help explain the infrequency of peptic ulcer.

The use of endoscopy in HIV-infected patients with dyspepsia should be based on the likelihood of an underlying opportunistic process that would require biopsy, the severity of symptoms, associated symptoms such as vomiting that may reflect severe disease and the need for endoscopic therapy. The dyspeptic HIV-infected patient without immune dysfunction should be managed similarly to any other patient. Neither randomized trials nor cost effectiveness analyses have compared $\mathrm{H}$ pylori serological testing with eradication therapy if positive to short term $\mathrm{H}_{2}$-receptor blocker or proton pump inhibitor therapy, or immediate endoscopy in the HIV-infected patient with dyspepsia.

\section{NAUSEA AND VOMITING}

As for dyspepsia, there are few data on the utility of endoscopy in HIV-infected patients with nausea and vomiting. The potential etiologies of nausea and vomiting are multiple, including central nervous system disorders, esophageal disease, gastric or duodenal abnormalities, hepatobiliary disease, systemic illness and medications. In the study by Bashir and Wilcox (5), of 11 patients undergoing upper endoscopy for nausea and vomiting, a specific cause was identified in only three; in two patients, esophageal candidiasis was found, although likely incidental, while the other patient had intestinal cryptosporidiosis. The latter patient also had diarrhea. Although the sample size of this study (5) was small, the results suggest that the overall yield of endoscopy for this indication is low. Given this low yield, it is also likely that barium studies of the upper gastrointestinal tract performed for nausea and vomiting are rarely helpful. Abdominal computed tomographic (CT) scanning may be useful to exclude pancreatic disease, but pain is usually the predominant symptom. Gastroparesis should be suggested by the history. Acute hepatitis may manifest as nausea but is usually evident by the physical examination and laboratory studies. Patients with type $B$ lactic acidosis caused by nucleoside analogs may present with nausea and vomiting and abnormal liver tests (36). As mentioned above, strong consideration should always be given to a drug-induced cause, which would require drug discontinuation as a 'therapeutic' trial. In our experience, medications are one of the most common etio- logical factors for nausea and vomiting in these patients. If endoscopy is performed, the duodenum should be biopsied when enteritis is suspected clinically or endoscopically.

\section{DIARRHEA}

In the HIV-infected patient with chronic diarrhea in whom colorectal symptoms are absent, consideration should be given to a small bowel etiology. Recent studies of HIVinfected patients with chronic diarrhea suggest that approximately $50 \%$ of patients have a parasitic cause, including small intestinal cryptosporidiosis or microsporidiosis (37). Although stool testing should be the first diagnostic test, Blanshard et al (37) found that multiple stool tests were nondiagnostic in $53 \%$ of patients with chronic diarrhea in whom a diagnosis was established by other means. Of the patients with documented cryptosporidiosis, evaluation of six stools appeared to maximize sensitivity. Nevertheless, although obtaining six stool tests further increased diagnostic yield over three stools, there still remained a substantial number of patients with false-negative tests. In our experience, obtaining six stool tests in these patients is highly impractical.

For the patient with chronic diarrhea who is at risk of opportunistic infection and in whom stool tests disclose no specific cause, endoscopic small bowel biopsy is reasonable to exclude a pathogen (38-41). In the study by Blanshard et al (37), both duodenal and rectal biopsies increased the yield for cryptosporidiosis over stool tests alone. We found a small bowel cause in $19 \%$ of patients with chronic diarrhea and multiple negative stool tests (39). Small bowel biopsy increases the yield over stool tests for the detection of intestinal MAC (42). The endoscopic appearance of the duodenum may also provide a clue to the presence of enteritis (42-44). Duodenal biopsies, rather than jejunal biopsies, obtained with the standard upper endoscope are generally sufficient for evaluation (37). Although small bowel biopsy may identify an infectious cause of the diarrhea, treatment options for the most frequently identified pathogens are limited (23). Thus, one might argue that the results of small bowel biopsy will infrequently alter therapy. Therefore, we believe endoscopy and small bowel biopsy should be individualized.

\section{ABDOMINAL PAIN}

As in any patient with abdominal pain, the location, character, severity, associated symptoms, and ameliorating and exacerbating features will determine the diagnostic possibilities. The causes of abdominal pain in HIV-infected patients are myriad and, as with the above symptom complexes, the severity of immunodeficiency dictates the differential diagnosis. Studies that have focused on the causes of abdominal pain in HIV-infected patients have shown a wide etiological spectrum, utility of clinical features for localization and relationship of etiology to immune function $(45,46)$. In patients with AIDS, severe abdominal pain may be caused by an opportunistic process in $65 \%$ or more of patients (45). The most frequent opportunistic infection causing significant abdominal pain in AIDS is CMV, usually of the colon. When 
the pain is severe and diffuse, enteritis, colitis and pancreatitis should be considered. Viscus perforation is manifested by an acute abdomen. Intestinal obstruction may be caused by a neoplasm such as lymphoma and KS or even adenocarcinoma. Right upper quadrant pain usually represents biliary tract disease $(45,46)$.

The use of upper endoscopy in patients with abdominal pain should be directed to those in whom upper abdominal pain is prominent and where luminal disease (gastric, duodenal) is suggested by the presence of associated symptoms, including nocturnal dyspepsia, refractory heartburn or esophageal complaints, nausea and vomiting, and hematemesis. If pancreatitis is suspected, abdominal CT rather than endoscopy should be performed. In patients with fever, severe pain usually in the hypochondrium and diarrhea, a colonic etiology should be considered, which would warrant endoscopic examination of the distal colorectum. However, abdominal CT, rather than endoscopy, is often the first test performed in such patients, which identifies colonic wall thickening or disease in another organ.

\section{UPPER GASTROINTESTINAL BLEEDING}

Upper gastrointestinal bleeding is an uncommon problem in HIV-infected patients, having been found in $6 \%$ of patients followed for six months in one prospective series (47). The short term prognosis of these patients is based on the stage of immunodeficiency, although bleeding may reduce survival (48). The etiologies of upper gastrointestinal bleeding are often related to AIDS, but diseases not associated with HIV disease, including peptic ulcer disease and Mallory-Weiss tear, can also occur $(47,48)$. In the patient consuming nonsteroidal anti-inflammatory drugs, peptic ulcer disease must always be considered. In one series (48), gastric and/or duodenal lymphoma was the most frequent cause of bleeding followed by esophagitis, and thrombocytopenia was commonly associated with bleeding. In our experience, esophageal ulcers due to opportunistic processes are an important cause of upper gastrointestinal bleeding in patients with AIDS. These findings on the causes of upper gastrointestinal bleeding in AIDS are similar to those of lower gastrointestinal bleeding where opportunistic processes (CMV) are the most frequent etiologies (49).

When bleeding is substantial, upper endoscopy is warranted regardless of the CD4 lymphocyte count because endoscopic therapy for hemostasis is likely necessary. As in any other patient, identification of an actively bleeding lesion warrants endoscopic therapy. However, it is important to determine the underlying cause of the bleeding lesion. Thus, sampling of the lesion by biopsy is important in the patient with AIDS; biopsies should be obtained from adjacent abnormal areas to avoid the bleeding point.

\section{CONCLUSIONS}

Upper endoscopy is an integral tool for the evaluation of upper gastrointestinal complaints in HIV-infected patients. When immunodeficiency is severe (ie, AIDS), endoscopy is most likely to identify an opportunistic infection or neo- plasm, and in this setting, mucosal biopsy is essential to establish a specific diagnosis to guide therapy. Nevertheless, it is important to remember that processes unrelated to HIV infection can occur in these patients regardless of the stage of immunodeficiency. Empirical therapy directed at the most common cause of symptoms can be helpful, especially antifungal therapy for esophageal complaints. The general principles of endoscopy in the immunocompetent patient should be similarly applied to these patients. However, there are unique problems of HIV-infected patients that require an expeditious but cautious use of endoscopy, and the appropriate use of mucosal biopsy and tissue sampling, as well as expert pathological support.

\section{REFERENCES}

1. Palella FJ Jr, Melaney KM, Moorman AC, Loveless MO, Fuhrer I. Declining morbidity and mortality among patients with advanced human immunodeficiency virus infection. HIV Outpatient Study Investigators. N Engl J Med 1998;338:853-60.

2. Gallant JE, Moore RD, Richman DD, Keruly J, Chaisson RE. Incidence and natural history of cytomegalovirus disease in patients with the advanced human immunodeficiency virus disease treated with zidovudine. The Zidovudine Epidemiology Study Group. J Infect Dis $1992 ; 166: 1223-7$

3. Mellors JW, Munoz A, Giorgi JV, et al. Plasma viral load and CD4 lymphocytes as prognostic markers of HIV-1 infection. Ann Intern Med 1997;126:946-54.

4. Vlahov D, Graham N, Hoover D, et al. Prognostic indicators for AIDS and infectious disease death in HIV-infected injection drug users. JAMA 1998;279:35-40.

5. Bashir RM, Wilcox CM. Symptom-specific use of upper gastrointestinal endoscopy in human immunodeficiency virus. infected patients yields high dividends. J Clin Gastroenterol $1996: 23: 292-8$.

6. Moore RD, Chaisson RE. Natural history of opportun istic disease in an HIV-infected urban clinical cohort. Ann Intern Med $1996 ; 124: 633-42$.

7. Mocroft A, Youle M, Phillips AN, et al. The incidence of AIDS-defining illnesses in 4883 patients with human immunodeficiency virus infection. Royal Free/Chelsea and Westminster Hospitals Collaborative Group. Arch Intern Med $1998 ; 158: 491-7$

8. Wilcox CM, Rabeneck L, Friedman S. AGA technical review: malnutrition and cachexia, chronic diarrhea, and hepatobiliary disease in patients with human immunodeficiency virus infection. Gastroenterology 1996;111:1724-52.

9. Wilcox CM. Esophageal disease in the acquired immunodeficiency syndrome: etiology, diagnosis, and management. Am J Med $1992 ; 92: 412-21$

10. Connolly GM, Hawkins D, Harcourt-Webster JN, Parsons PA, Husain OA, Gazzard BG. Oesophageal symptoms, their causes, treatment, and prognosis in patients with the acquired immune deficiency syndrome. Gut 1989;30:1033-9.

11. Bonacini M, Young T, Laine L. The causes of esophageal symptoms in human immunodeficiency virus infection: A prospective study of 110 patients. Arch Intern Med 1991;151:1567-72.

12. Wilcox CM, Alexander LN, Clark WS, Thompson SE III. Fluconazole compared with endoscopy for human immunodeficiency virus-infected patients with esophageal symptoms. Gastroenterology $1996 ; 110: 1803-9$.

13. Wilcox CM. Evaluation of a technique to evaluate the underlying mucosa in patients with AIDS and severe Candida esophagitis. Gastrointest Endosc 1995;42:360-3.

14. Wilcox CM, Schwartz DA, Clark WS. Esophageal ulceration in human immunodeficiency virus infection: Causes, response to therapy, and long-term outcome. Ann Intern Med 1995;122:143-9.

15. Dieterich DT, Wilcox CM. Diagnosis and treatment of esophageal diseases associated with HIV-infection. Practice Parameters Committee of the American College of Gastroenterology. Am J Gastroenterol 1996;91:2265-8.

16. Wilcox CM. Time course of clinical response to fluconazole for 
Candida oesphagitis in AIDS. Aliment Pharmacol Ther $1994 ; 8: 347-50$

17. Gil A, Lavilla P, Valencia E, et al. Safety and efficacy of fluconazole treatment for Candida oesophagitis in AIDS. Fostgrad Med J $1991 ; 67: 548-52$.

18. Rabeneck L, Laine L. Esophageal candidiasis in patients infected with the human immunodeficiency virus. A decision analysis to assess cost-effectiveness of alternative management strategies. Arch Intern Med 1994;154:2705-10.

19. Wilcox CM, Straub RF, Clark WS. Prospective evaluation of oropharyngeal findings in human immunodeficiency virus. infected patients with esophageal ulcer. Am J Gastroenterol $1995 ; 90: 1938-41$.

20. Barbaro G, Barbarini G, Calderon W, Grisorio B, Alcini P, Di Lorenzo G. Fluconazole versus itraconazole for candida esophagitis in acquired immunodeficiency syndrome. Gastroenterology $1996 ; 111: 1169-77$

21. Laine L, Dretler RH, Conteas CN, et al. Fluconazole compared with ketoconazole for the treatment of Candida esophagitis in AIDS. A randomized trial. Ann Intern Med 1992;117:655-60.

22. Wilcox CM, Darouiche RO, Laine L, Moskovitz BL, Mallegol I, Wu J. A randomized, double-blind comparison of itraconazole oral solution and fluconazole tablets in the treatment of esophageal candidiasis. J Infect Dis 1997;176:227-32.

23. Wilcox CM, Mönkemüller KE. Review article: the therapy of gastrointestinal infections associated with the acquired immunodeficiency syndrome. Aliment Pharmacol Ther 1997;11:425-43.

24. Wilcox CM, Straub RF, Alexander LN, Clark WS. Etiology of esophageal disease in human immunodeficiency virus infected patients who fail antifungal therapy. Am J Med 1996;101:599-604.

25. Wilcox CM, Schwartz DA. Comparison of two corticosteroid regimens for the treatment of HIV-associated idiopathic esophageal ulcer. Am J Gastroenterol 1994;89:2163-7.

26. Alexander LN, Wilcox CM. A prospective trial of thalidomide for the treatment of HIV-associated idiopathic esophageal ulcers. AIDS Res Hum Retroviruses 1997;13:301-4.

27. Connolly GM, Forbes A, Gleeson JA, Gazzard BG. Short communication investigation of upper gastrointestinal symptoms in patients with AIDS. AIDS 1989;3:453-6.

28. Baehr PH, McDonald GB. Esophageal infections: risk factors, presentation, diagnosis, and treatment. Gastroenterology 1994;106:509-32.

29. Wilcox CM, Straub RF, Schwartz DA. A prospective evaluation of biopsy number for the diagnosis of viral esophagit is in patients with HIV infection and esophageal ulcer. Gastrointest Endosc $1996 ; 44: 587-93$.

30. Marano BJ, Smith F, Bonanno CA. Helicobacter pylori prevalance in acquired immunodeficiency syndrome. Am J Gastroenterol $1993 ; 88: 687-90$.

31. Battan R, Raviglione MC, Palagiano A, et al. Helicobactor pylori infection in patients with acquired immune deficiency syndrome. Am J Gastroenterol 1990;85:1576-9.

32. Nielsen H, Anderson LP. Serodiagnosis of Helicobacter pylori infection in patients with human immunodeficiency virus infection. APMIS $1995 ; 103: 689-92$.
33. Edwards PD, Carrick J, Turner J, Lee A, Mitchell H, Cooper DA. Helicobacter pylori-associated gastritis is rare in AIDS: Antibiotic effect or consequences of immunodeficiency? Am J Gastroenterol $1991 ; 86: 1761-4$

34. Lake-Bakaar G, Quadros E, Beidas S, Elsakr M, Tom W, Wilson DE. Gastric secretory failure in patients with the acquired immunodeficiency syndrome (AIDS). Ann Intern Med $1988 ; 109: 502-4$.

35. Welage LS, Carver PL, Revankar S, Pierson C, Kauffman CA. Alterations in gastric acidity in patients infected with human immunodeficiency virus. Clin Infect Dis 1995;21:1431-8.

36. Sundar K, Suarez M, Banogoon PE, Shapiro JM. Zidovudine-induced fatal lactic acidosis and hepatic failure in patients with acquired immunodeficiency syndrome: Report of two patients and review of the literature. Crit Care Med 1997;25:1425-30.

37. Blanshard C, Francis N, Gazzard BG. Investigation of chronic diarrhea in acquired immunodeficiency syndrome. A prospective study of 155 patients. Gut 1996;39:824-32.

38. Connolly GM, Forbes A, Gazzard BG. Investigation of seemingly pathogen-negative diarrhea in patients infected with HIV1. Gut $1990 ; 31: 886-9$.

39. Wilcox CM, Schwartz DA, Cotson is GA, Thompson WE III. Evaluation of chronic unexplained diarrhea in human immunodeficiency virus infection: determination of the best diagnostic approach. Gastroenterology 1996;110:30-7.

40. Bown JW, Savides TJ, Mathews C, Isenberg J, Behling C, Lyche KD. Diagnostic yield of duodenal biopsy and aspirate in AIDS-associated diarrhea. Am J Gastroenterol 1996;91:2289-92.

41. Bini EJ, Cohen J. Diagnostic yield and cost-effectiveness of endoscopy in chronic human immunodeficiency virus-related diarrhea. Gastrointest Endosc 1998;48:354-61.

42. Gray JR, Rabeneck L. Atypical mycobacterial infection of the gastrointestinal tract in AIDS patients. Am J Gastroenterol $1989 ; 84: 1521-4$.

43. Chalasani N, Lazenby AJ, Wilcox CM. Unusual endoscopic features of gastric and duodenal cryptosporidiosis in AIDS. Gastrointest Endosc 1997:45:525-7.

44. Chalasani N, Wilcox CM, Hunter HT, Schwartz DA. Endoscopic features of gastroduodenal cryptococcosis in AIDS. Gastrointest Endosc 1997:45:315-7.

45. Parente F, Cernuschi M, Antinori S, et al. Severe abdominal pain in patients with AIDS: Frequency, clinical aspects, causes and outcome. Scand J Gastroenterol 1994:29:511-5.

46. Thuluvath PJ, Connolly CM, Forbes A, Gazzard BG. Abdominal pain in HIV infection. QJ Med 1991;78:275-85.

47. Parente F, Chernuschi M, Valsecchi M, et al. Acute upper gastrointestinal bleeding in patients with AIDS: A relatively uncommon condition associated with reduced survival. Gut $1991 ; 32: 987-90$

48. Cappell MS, Geller AJ. The high mortality of gastrointestinal bleeding in HIV-seropositive patients: A multivariate analysis of risk factors and warning signs of mortality in 50 consecutive patients. Am J Gastroenterology 1992;87:815-24.

49. Chalasani N, Wilcox CM. Etiology and outcome of lower gastrointestinal bleeding in patients with AIDS. Am J Gastroenterol $1998 ; 93: 175-8$. 


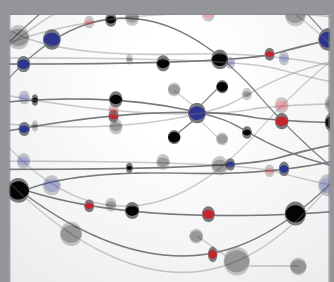

The Scientific World Journal
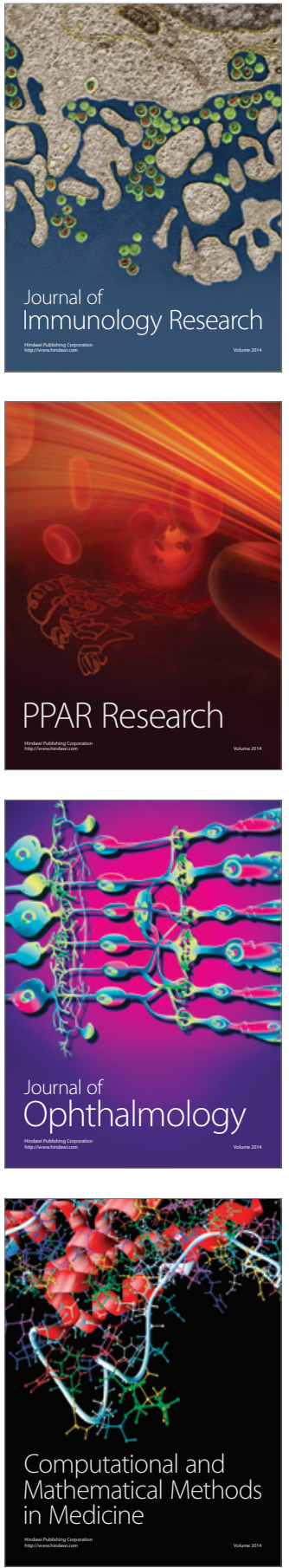

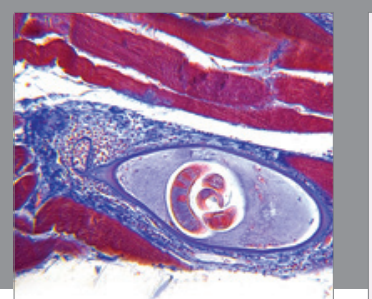

Gastroenterology Research and Practice

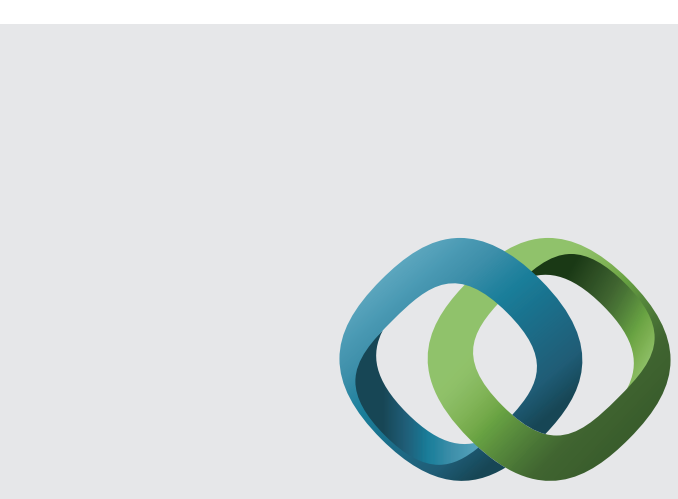

\section{Hindawi}

Submit your manuscripts at

http://www.hindawi.com
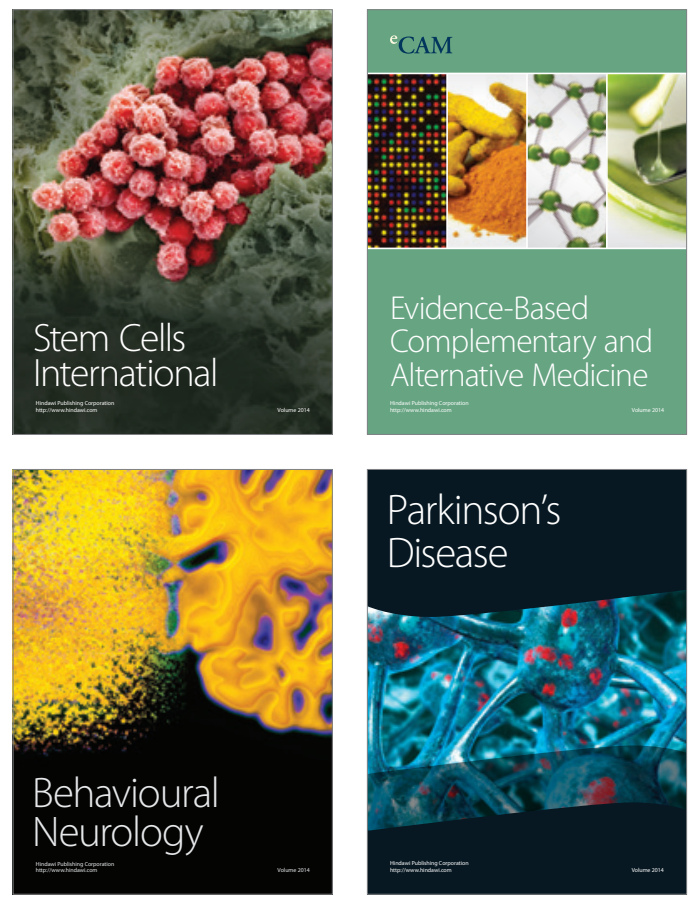
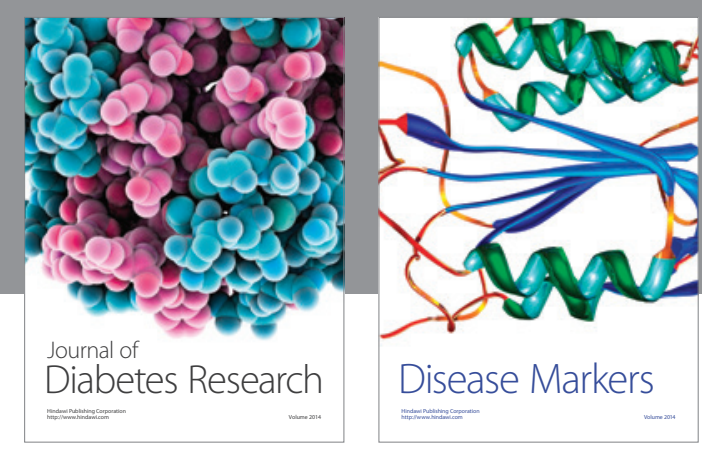

Disease Markers
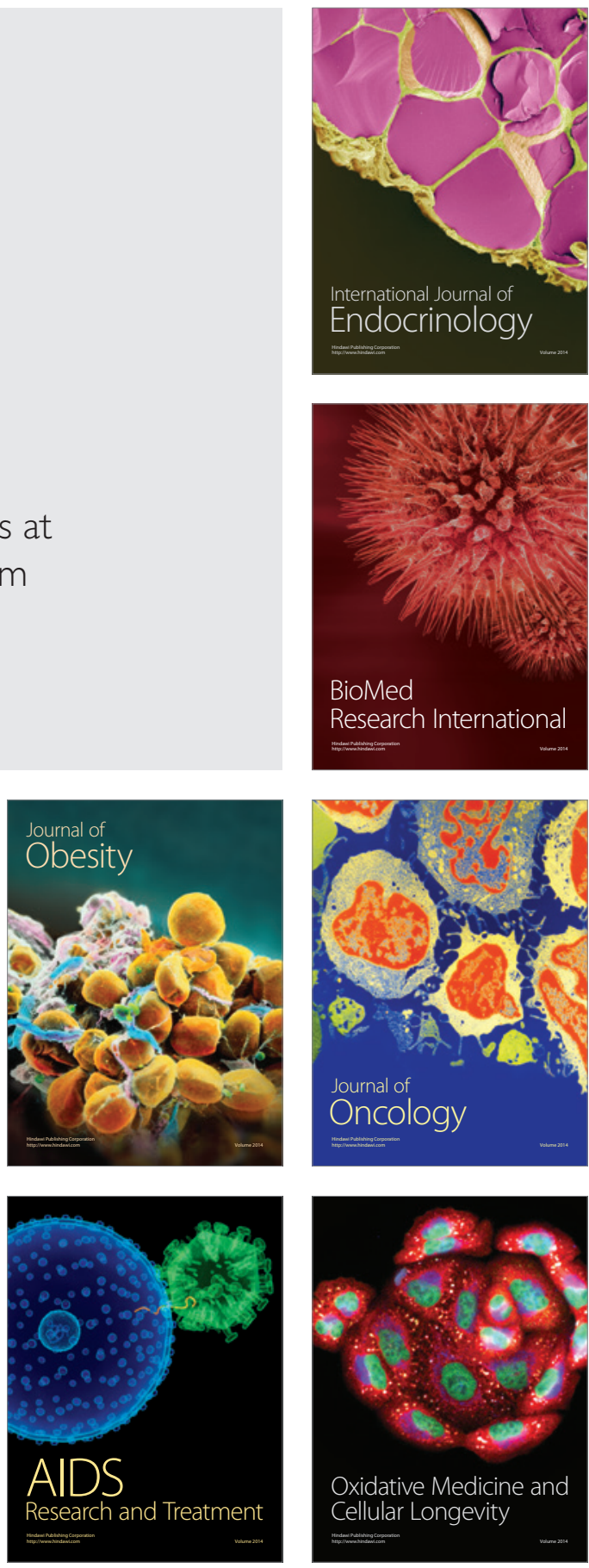